\title{
Prologue: Quality of Life in South America
}

\author{
Graciela Tonon $^{1,2} \cdot$ Denise Benatuil ${ }^{2}$
}

Published online: 7 April 2018

(C) Springer Science+Business Media B.V., part of Springer Nature and The International Society for Qualityof-Life Studies (ISQOLS) 2018

South America is a region that presents particularities which are not much visualized in quality of life studies, this is the reason we decided to organize a Special Issue of Applied Research in Quality of Life dedicated to the quality of life of population that live in South America. We are presenting a collection of studies, theoretical and empirical, which shows the plurality of South American's realities from different dimensions: the political, the social, the psychological, the cultural and the economical view.

The different articles that compose this Special Issue speak about: citizens' life satisfaction and confidence in national institutions in South American countries; the inequalities and the difficulties for full realization of their rights that affected children in South American countries; the satisfaction with their lives of adolescents in Venezuela; the daily life of working children in Peru; the subjective well-being of adolescents in Chile; leisure, free time and well-being of children in Buenos Aires Province, Argentina; the subjective well-being of the population in Uruguay; the habitability conditions in periurban areas in Mar del Plata, Argentina, the mapping of temporal changes of quality of life conditions reflecting the well-being of individuals, communities and urban areas in Rosario, Argentina; the self-perceived health among school-aged adolescents in Brazil; the subjective well-being of Brazilian children from different family settings; the bullying and cyber bullying of Chilean adolescents; the sense of community and life satisfaction of Chilean adolescents; the subjective well-being, life satisfaction and interpersonal relationships associated to socio-demographic and contextual variables in Brazil.

In the first article Walter Toscano and Damian Molgaray presents a bibliographical and systematize analysis of the available literary productions, of the research corpus developed on South America by different academic/research groups, regarding quality

Graciela Tonon

gtonon1@palermo.edu

Denise Benatuil

ebenat@palermo.edu

1 Master Program in Social Sciences, Universidad de Palermo, Buenos Aires, Argentina

2 CICS-UP, Faculty of Social Sciences, Universidad de Palermo, Buenos Aires, Argentina 
of life - while taking into consideration emblematic research devoted to well-being, life satisfaction and happiness. The authors explain that South America can be characterized as a region of contrasts, with a vast diversity of natural resources where immigrants from different parts of Europe, Asia and other countries of Latin America live together in a peaceful coexistence. It is known for its strong political tension generated by demand of transparency in the members of the ruling class, together with constant struggles on account of the significant inequalities regarding access to health, habitation, education, and other basic social services.

The second article by Maccia and Plagnol, speaks about life satisfaction and confidence in national institutions of citizens in South American countries considering that a number of them experienced turbulent democratic, political and economic crises over the last 40 years. The authors used the eight waves of the Gallup World Poll collected between 2009 and 2016 across ten South American countries to investigate to what extent people's confidence in financial institutions, the honesty of elections, the military, the judicial system, the national government and the police is associated with people's current and expectation of future life satisfaction and well-being.

In the article entitled South American Children's Quality of Life: Intra-urban disparities along life-cycle indicators, Born, Colamarco, Delamónica and Minujín study the inequalities and the difficulties for full realization of their rights that affected children in South American countries. Based on housing characteristics, income level and parents' educational status, the authors classified the households in three groups: experiencing highly deprived, moderately deprived or non-deprived living conditions. Relative and absolute gaps for several indicators were analyzed to compare children living in highly deprived and non-deprived households.

Márquez, Holgado and Maya Jariego in their article Innovation, dosage and responsiveness in the implementation of the program "Edúcame Primero Peru" for reducing child labour, presented the description of the implementation of a program to prevent child labour in risk contexts. The author describe the program, the implementation, the groups and includes the voice and discourse of the protagonists, as agents. This program had already been implemented in other Latin American countries with good results. It promotes respect and understanding for diversity; foments positive relationships with family and community and encourages further education. Concerning the methodology, the authors use qualitative methods to describe the groups and to include the voice and discourse of the protagonists, as agents and also quantitative methods to evaluate results as the permanence in the program, attendance, responsiveness, abandonment and commitment of the participants.

Schutz and Bedin presented in their article Subjective well-being of Brazilian children from different family settings, the relationship between the family context and the well-being. They studied the aspects of family relationships that may affect the well-being of children in a quantitative study, working with a sample of 2135 boys and girls, from 9 to 13 years old living in a Brazilian southern State. The authors use three well-being scales (PWI-SC, BMSLSS, GDSI), and divide the family settings into four groups: intact, single-parent, stepfamilies, multigenerational. To evaluate differences between groups a Multivariate Analysis of Variance (MANOVA) were used. This article has interesting results; as other studies show that the well-being decreases with increasing the age. 
In the article by Varela, Guzmán, Alfaro and Reyes, entitled Bullying, Cyber bullying, Student Life Satisfaction and the Community of Chilean Adolescents, the authors addressed a theme frequent, current and central for adolescents. Negatives experiences at school, such as bullying and cyberbullying can have an adverse impact on adolescent's life satisfaction that can expand to different domains of their lives including community variables. This is a quantitative study, whose goal was to examine the association between peer victimization, life satisfaction and community supports work with Chilean adolescents from 14 to 19 years. The main findings showed a negative association between bullying and cyberbullying behavior on community support through life satisfaction, also peer victimization can have negative consequences for youth life satisfaction, expanding to feeling less support from the community. Community prevention efforts can provide then emotional support for youth victims of bullying and cyber bullying.

Ramos dos Santos, Castellá Sarriera and Bedin present the article Subjective wellbeing, life satisfaction and interpersonal relationships associated to sociodemographic and contextual variables. This is a quantitative study made with a big sample, 2280 children from 9 to 13 years old, from Brazil -the capital Porto Alegre and four other country cities in the state of Rio Grande do Sul-. The authors compare the participants according age, residence area and type of school (public and private). They arrive to interesting conclusions concerning the correlation between housing context and the kind of relationships that the children enable with their families and their peers. And also atlases the relation between the kind of school (public or private) and mean they give to family and friends.

Tonon, Laurito and Benatuil present an article dedicated to the study of leisure, free time and well-being of children living in Buenos Aires Province, Argentina, conceiving children as active agents and protagonists of the research, focusing on their own outlook and using their own words. In this article the authors analyzed the use of free time, free-time activities and children's well-being as part of the international research network The Children's Worlds. The sampling consisted of 373 ten-year old children, studying at public and private institutions. The instrument used was the ISCWeB. The results showed that children are highly satisfied with the use of their free time; watching television is the most frequent activity while reading for pleasure and studying with friends are the least frequent one. Also the link between subjective well-being and the use of free time was verified.

Peréz-Delgado in the article Adolescents satisfaction with life in Venezuela, assess the satisfaction with life in a context of great complexity. In this context, the author aims to measured well-being and life satisfaction in a sample of 796 students from public schools and private schools. It was a correlation study with a cross-cutting nonexperimental design, using the PWI and the ESCVP (Tonon, 2009). The main findings showed differences in satisfaction for students of public schools in contrast with students of private schools. Also, differences in specific indicators regarding gender, with greater satisfaction of the male group. Concerning the Index of national wellbeing, the higher satisfaction indicator was the possibility of doing business and the lower were related to national security (public safety) and with the government; and the lowest satisfaction indicator was related to the decisions of the government to attend the needs of the population. Finally, this article once again shows the importance of considering the environments perceived by the persons to evaluate their well-being. 
Gonçalves Câmara and Wachholz Strelhow presented a study entitled Self-perceived health among school-aged adolescents. This work was made with 3360 students from the metropolitan area of Porto Alegre, Brazil. The authors identify which aspects regarding the dimensions of quality of life -body image, relationships with family and friends, rest and free time, school, physical, psychological and social well-being and lifestyles- constitute predictors of self-perceived health. A quantitative methodology and different instruments - scales and questionnaire- were use. The results point as important aspects for self-perception of health: body satisfaction and perception of being thinner, healthy eating habits, well-being, relationships of trust with brothers.

Guzmán, Alfaro and Varela, in the article Sense of Community and Life Satisfaction in Chilean Adolescents propose to contribute to the understanding of life satisfaction in Chilean adolescents. The authors work with 438 Chilean adolescents, using the Sense of Community Scale, and the PWI-SC. This is a quantitative work that include descriptive and multivariate analyses. The preliminary findings support the hypothesis that the perception of community variables influences the assessment that adolescents have on their lives. This article show that sense of community and life satisfaction are related, independently demographic variables. Also, the perception of the sense of community has a positive effect that enhances the overall assessment that adolescents make about their lives. On the other hand, territorial belongingness was not significantly associated with life satisfaction however, adolescents reported a significant association between their community relationships and life satisfaction, showing identification with their human interactions.

Salas and Vigorito presented the quality of life assessments, subjective well-being and adaptation in Uruguay. The authors consider that subjective well-being in three domains (life satisfaction, economic situation and housing) is affected by adaptation to objective well-being trajectories. Although adaptive preferences and adaptation had been addressed in the empirical literature for developed countries, there is scarce evidence for developing countries due to the lack of suitable panel data sets. The authors carry out an empirical exercise based on three waves of a longitudinal study developed in Uruguay in 2004, 2006 and 2011/12 (Estudio Longitudinal de Bienestar en Uruguay), performing a multivariate analysis, correcting for potential endogenous problems. The main findings showed that the present levels of life, income and housing satisfaction are positively correlated with the corresponding contemporary and lagged objective variable of interest; rejecting the hypothesis of adaptation in all the domains considered. The average objective well-being of the reference group is not associated to present life satisfaction. However, life and housing satisfaction are positively correlated to the average subjective well-being of their reference group.

Mapping dynamic indicators of quality of life: a case in Rosario, Argentina is the article wrote by Javier Martinez dedicated to mapping temporal changes of quality of life conditions reflecting the well-being of individuals, communities and urban areas has the potential to identify spatial patterns and trends towards prosperous and just societies. This article presents an approach to map and to compare quality of life variations in time and space across districts and neighborhood areas of the city of Rosario, Argentina. Census data (1991, 2001 and 2010) have been used to map and trace the trajectories of neighborhood areas in relation to objective quality of life conditions. As a result, trends in improving the quality of life and reducing inequalities between neighborhood areas are visualized. Three main outcomes have been found: 
divergence, convergence and maintenance of the status quo. The article concludes reflecting on the emerging patterns and critically exploring how these mappings and representations can be used to better inform policy makers and potentially improve community well-being.

Zulaica and Oriolani studied the quality of life and habitability conditions in periurban areas of Southern Mar del Plata, Argentina, from a multi-method study. They said that peri-urban areas in Latin America exhibit significant social and environmental problems that affect the quality of life of their inhabitants. A synthetic index was constructed based on the concept of habitability, which is directly linked to the notion of quality of life, and integrates six dimensions (health, housing, accessibility, education, economy, and environment). Indicators were obtained mainly from the last national censuses (2001-2010). Subsequently, semi-structured interviews (20152016) were conducted in the areas affected by the most critical habitability conditions identified by the index in order to deepen the perception and appreciation of the individuals' experience about their quality of life. The results obtained reveal unequal access to infrastructure, services, equipment, adequate housing, and urban land, among others, especially noticed between the coastal and inland sectors.

The studies were developed using different methodologies: quantitative methods, qualitative methods, and multi-methods and with different groups: children, young people, adults. The final aim of this Special Issue is to present the quality of life/wellbeing of people in South America, considering it as a particular region of our planet.

We want to thanks all the colleagues that participated in this Special Issue, making visible South America's quality of life to the rest of the world.

We specially thanks Daniel Shek, Editor of the Applied Research in Quality of Life, Official Journal of the International Society for Quality of Life Studies, that gives us the possibility of edit this Special Issue and to Alex Michalos, Joe Sirgy and Richard Estes that founded this Journal more than a decade ago, for their permanent support to our work in Latin America. 